\title{
Principles of Molecular Photochemistry - An Introduction
}

Hugh Burrows*

\author{
Nicholas J. Turro, V. Ramamurthy e J. C. Scaiano \\ University Science Books, Sausalito, CA, 2009. \\ 495 páginas * ISBN 978-1891389573
}

Quando iniciei a minha carreira de investigação em fotoquímica, há mais de quatro décadas, só havia dois livros recentes dedicados à área, "Molecular Photochemistry" de N. J. Turro, e "Photochemistry" por J. G. Calvert e J. N. Pitts. Os dois continuam a ser excelentes fontes de informação, mas, o livro mais pequeno, o de Nick Turro (aproximadamente 300 páginas), tinha a vantagem de, além de introduzir rapidamente um aprendiz como eu na área, induzir o gosto pela fotoquímica. O livro estava muito bem escrito e permitia dominar com alguma facilidade os conceitos básicos. Começou a ser cada vez mais difícil encontrar o livro e, com o tempo, começaram também a faltar os novos desenvolvimentos, típicos de uma área de crescimento rápido e que tiveram lugar desde a sua publicação, em 1964. Em 1978, Turro publicou um livro bastante maior e mais abrangente, intitulado "Modern Molecular Photochemistry", que foi considerado por um grande número de químicos e físicos, como eu, o livro de referência na área.

Três décadas depois temos o há muito esperado "Principles of Molecular Photochemistry - An Introduction". Este novo livro tem por base as mesmas ideias dos seus antecessores, mas beneficia de um tratamento mais

Universidade de Coimbra, burrows@ci.uc.pt abrangente das bases espectroscópicas e fotofísicas da fotoquímica e também da inclusão dos desenvolvimentos mais recentes da área, nomeadamente na parte teórica. Este novo livro beneficiou também da colaboração de dois co-autores, V. Ramamurthy e J. C. (Tito) Scaiano, cientistas muito respeitados dentro e fora da comunidade fotoquímica.

A descrição dos conceitos mais importantes de espectroscopia e fotofísica assenta numa base pictórica, em vez de descrições matemáticas detalhadas, e, em sete capítulos, apresenta aos estudantes as ideias mais importantes da fotoquímica. A filosofia descritiva do livro fundamenta a sua utilização como um "primer" de fotoquímica. O livro é relativamente grande (495 páginas), mas é fácil estudar cada secção separadamente.

O livro começa com uma visão global da fotoquímica. A seguir apresenta os estados electrónicos e vibracionais e a importância do acoplamento de spin dos electrões. O tratamento de tópicos base como o princípio de FranckCondon e o acoplamento spin-orbital é bastante elegante, conduzindo de uma forma natural aos capítulos seguintes sobre a transições radiativas e não-radiativas entre estados electrónicos. A apresentação conceptual é excelente para disciplinas de licen-

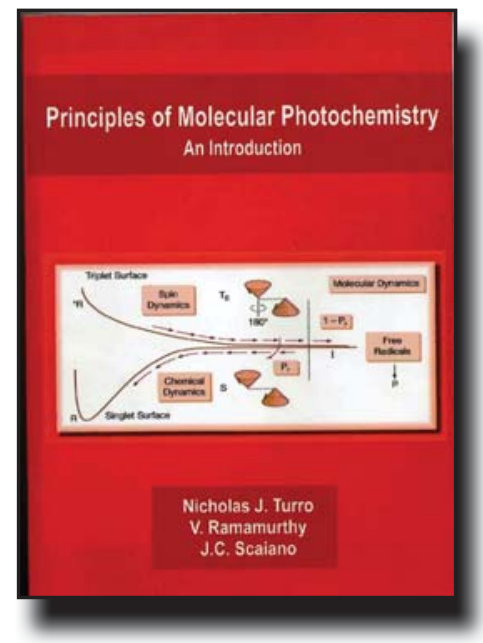

ciatura ou de pós-graduação em fotoquímica. Facilitará também a sua utilização por estudantes de áreas afins, como a fotobiologia ou as ciências dos materiais. A bibliografia detalhada facilitará ainda o acesso a tratamentos mais quantitativos dos processos espectroscópicos e fotofísicos.

Na sequência surge um capítulo sobre a teoria da fotoquímica orgânica. Dado o interesse dos três autores, não surpreende que seja dada ênfase a sistemas orgânicos. No entanto serve perfeitamente como ponto de partida para estudos de sistemas inorgânicos e organometálicos, podendo facilmente ser acompanhado por livros ou artigos de revisão destas áreas. Na secção final, há discussão de vários aspectos dos processos de transferência de energia e de electrão no estado excitado, incluindo muitos exemplos relevantes e recentes.

O tratamento da fotoquímica orgânica é abrangente, a apresentação excelente e o preço acessível. Recomendo vivamente este livro a estudantes, professores e investigadores de fotoquímica, e de áreas associadas. Para os que pretendem um tratamento mais profundo, tenho o prazer de recomendar o livro associado, o "Modern Molecular Photochemistry of Organic Molecules" (ISBN 978-1891389252), pelos mesmos autores. 